Published in final edited form as:

Ann Intern Med. 2018 April 17; 168(8): 533-540. doi:10.7326/M17-2871.

\title{
Direct-Acting Antiviral Prophylaxis in Kidney Transplantation From Hepatitis C Virus-Infected Donors to Noninfected Recipients: An Open-Label Nonrandomized Trial
}

\author{
Christine M. Durand ${ }^{1}$, Mary G. Bowring ${ }^{2}$, Diane M. Brown ${ }^{1}$, Michael A. Chattergoon ${ }^{1}$, Guido \\ Massaccesi $^{1}$, Nichole Bair ${ }^{2}$, Russell Wesson ${ }^{2}$, Ashraf Reyad ${ }^{2}$, Fizza F. Naqvi ${ }^{1}$, Darin \\ Ostrander $^{1}$, Jeremy Sugarman ${ }^{1,3}$, Dorry L. Segev ${ }^{2}$, Mark Sulkowski ${ }^{1}$, and Niraj M. Desai ${ }^{2}$ \\ ${ }^{1}$ Department of Medicine, Johns Hopkins University School of Medicine, Baltimore, MD \\ ${ }^{2}$ Department of Surgery, Johns Hopkins University School of Medicine, Baltimore, MD \\ ${ }^{3}$ Berman Institute of Bioethics, Johns Hopkins University, Baltimore, MD
}

\section{Abstract}

Background-Given the high mortality rate for those with end-stage kidney $\mathrm{d}$ sease on dialysis and the efficacy and safety of current hepatitis $\mathrm{C}$ virus (HCV) treatments, currently-discarded kidneys from $\mathrm{HCV}$-infected (HCV+) donors may be a neglected public health resource.

Objective-To determine the tolerability and feasibility of kidney transplantation (KT) from $\mathrm{HCV}+$ donors to $\mathrm{HCV}$-uninfected recipients (HCV D+/R-) in combination with direct-acting antivirals (DAAs) as pre- and post-transplant prophylaxis.

Design-Open-label, non-randomized trial. (ClinicalTrials.gov: NCT02781649)

Corresponding authors: Christine M. Durand, MD, Department of Medicine, Johns Hopkins School of Medicine, 1830 East Monument Street, Room 450D, Baltimore, MD 21205, christinedurand@ jhmi.edu, Phone: (410) 955-5684. Niraj M. Desai, MD, Department of Surgery, Johns Hopkins School of Medicine, 720 Rutland Avenue, Ross 771, Baltimore, MD 21205, ndesai13@jhmi.edu, Phone: (410) 502-5198.

Disclosure of Conflicts of Interest

C. Durand has received research grants from Bristol Meyers Squibb, Gilead Sciences Merck Pharmaceuticals, and Viiv Healthcare, and has served as a scientific advisor for Bristol Meyers Squibb, Gilead Sciences, and Merck Pharmaceuticals. J. Sugarman serves on Merck KGaA's Bioethics Advisory Panel and Stem Cell Research Oversight Committee; and Quintile's Ethics Advisory Panel. M. Sulkowski served as scientific advisor for AbbVie, Gilead Sciences, Cocrystal, Janssen, Merck Pharmaceuticals, Trek and also received research grants from AbbVie, Gilead Sciences, and Merck Pharmaceuticals. N. Desai has served as a scientific advisor for Merck Pharmaceuticals.

Authorship Contributions

Conception and design: C. Durand, M. Chattergoon, M. Sulkowski, N. Desai.

Analysis and interpretation of the data: C. Durand, M. Bowring, D. Brown, M. Chattergoon, M. Sulkowski, N. Desai.

Drafting of the article: C. Durand, M. Bowring.

Critical revision for important intellectual content: C. Durand, M. Bowring, D. Brown, M. Chattergoon, F. Naqvi, D. Ostrander, J. Sugarman, D. Segev, M Sulkowski, N Desai.

Final approval of the article: C. Durand, M. Bowring, D. Brown, M. Chattergoon, G. Massaccesi, J. Sugarman, N. Bair, R. Wesson, A. Reyad, F. Naqvi, D. Ostrander, J. Sugarman, D. Segev, M Sulkowski, N Desai.

Provision of study materials or patients: D. Brown, D. Ostrander, N. Bair, R. Wesson, A. Reyad, Fizza F. Naqvi.

Statistical expertise: M. Bowring.

Obtaining of funding: C. Durand, M Sulkowski, D. Ostrander, N. Desai.

Administrative, technical or logistic support: D. Brown, M. Chattergoon, G. Massaccesi, N. Bair, R. Wesson, A. Reyad, F. Naqvi, D.

Ostrander.

Collection and assembly of data: M. Bowring, D. Brown, G. Massaccesi, N. Bair. 
Setting一-Single-center.

Participants-10 HCV-uninfected KT candidates over the age of 50 years with no available living donors.

Intervention-KT from deceased donors ages 13-50 years with a positive HCV RNA and HCV antibody test. All recipients received a dose of grazoprevir $100 \mathrm{mg} / \mathrm{elbasvir} 50 \mathrm{mg}$ (GZR/EBR) immediately prior to transplant. For genotype 1 donors, recipients continued GZR/EBR for 12 weeks post-transplant; for genotype 2 or 3 donors, sofosbuvir $400 \mathrm{mg}$ was added to GZR/EBR for 12 weeks of triple-therapy.

Measurements-The primary safety outcome was the incidence of adverse events related to GZR-EBR. The primary efficacy outcome was the proportion recipients with HCV RNA less than the lower limit of quantification 12 weeks after prophylaxis.

Results-Among $10 \mathrm{HCV}$ D+/R- there were no treatment-related adverse events and HCV RNA was not detected in any recipient 12 weeks after treatment.

Limitations-Nonrandomized study design and small number of patients.

Conclusions-Pre- and post-transplant HCV treatment was safe and prevented chronic hepatitis $\mathrm{C}$ in HCV D+/R- KT. If confirmed in larger studies, this strategy should markedly expand organ options and reduce mortality for HCV- KT candidates.

\section{INTRODUCTION}

More than 420,000 individuals require hemodialysis for end-stage kidney disease in the United States.(1) These patients face a high mortality rate: 169 per 1,000 patients-years compared to 30 per 1,000 patient-years for kidney transplant (KT) recipients.(1) Furthermore, the survival benefit of KT has been well established $(2,3)$ and persists even with the use of kidneys from marginal donors.(4) However there is a severe shortage of organs for transplantation. Depending on geography, waiting times for a KT can be up to 10 years and it is estimated that more than $50 \%$ of candidates on the waitlist will die prior to receiving a transplant. $(5,6)$ Thus, expansion of the donor pool would have a significant public health benefit.

Kidneys from hepatitis $\mathrm{C}$-infected $(\mathrm{HCV}+)$ deceased donors are underutilized. Between 2005-2014, $2698 \mathrm{HCV}+$ donor kidneys that were recovered in the United States with the intent of transplantation were discarded.(7) A national study demonstrated that $\mathrm{HCV}+$ donor kidneys are 2.9 times more likely to be discarded compared to HCV- donor kidneys of the same quality despite providing a survival benefit compared to remaining on dialysis.(8) This excess discard might be due in part to a lack of $\mathrm{HCV}+$ transplant candidates for these organs, as well as an increasing number of available $\mathrm{HCV}+$ deceased donors, likely the result of the drug overdose-death epidemic.(9-11) HCV+ donors are, in general, young with few other medical comorbidities, and KT outcomes from these donors have been excellent. (12)

In the past, transmission of $\mathrm{HCV}$ from donor to recipient was a serious concern. However, the landscape of HCV changed in 2013 with the introduction of direct-acting antiviral 
(DAAs) with high cure rates even in KT.(13-17) In 2015, the once daily fixed-dose combination of the NS3/4A protease inhibitor grazoprevir (GZR) and the NS5A inhibitor elbasvir (EBR) was approved for use in individuals with impaired renal function and HCV genotype 1a infection.(18) For genotype 2 and 3 infection, the NS5B inihibitor sofosbuvir (SOF) is highly active (19). Additional trials have demonstrated the efficacy of GZR-EBR in combination with SOF for genotype 3 infection(20, 21)

As such, there has been growing interest in the use of $\mathrm{HCV}+$ donor (HCV D+) organs for transplantation into HCV-uninfected recipients (HCV D+/R-).(7, 22, 23) The objective of our study was to explore a strategy to prevent $\mathrm{HCV}$ infection in $\mathrm{HCV}$ - recipients following $\mathrm{KT}$ from $\mathrm{HCV}+$ donors. As such, we investigated the feasibility and tolerability of GZREBR +/- SOF prophylaxis in an open-label, single-center trial at Johns Hopkins University (Exploring transplants using hepatitis-C infected kidneys for $\mathrm{HCV}$-negative recipients [EXPANDER]; ClinicalTrials.gov number, NCT02781649).

\section{METHODS}

\section{Study Population}

KT candidates on the deceased donor transplant waiting list at Johns Hopkins Hospital who were $\geq 50$ years of age were eligible if they were receiving hemodialysis, peritoneal dialysis or had a glomerular filtration rate of $<15 \mathrm{ml} / \mathrm{min}$ for $\geq 90$ days. Candidates had to test negative for HCV by antibody and RNA and be without risk factors for HCV acquisition besides being on hemodialysis. Eligible patients could not have any living donors available nor have a prior history of a solid organ transplant. Recipients could not be listed for for a multi-organ transplant or receive a blood-type incompatible kidney transplant. Patients were ineligible if they had HIV infection, active hepatitis B virus infection, cirrhosis or a history of liver disease such as non-alcoholic steatohepatitis.

\section{Study Design}

After providing written informed consent, participants were listed with the United Network for Organ Sharing (UNOS) with a status of "willing to accept an HCV+ organ." The JHH transplant team then received $\mathrm{HCV}+$ donor kidney offers for the participant from UNOS according to standard allocation policies. Eligible donors had to be between 13-50 years of age and have a positive qualitative HCV nucleic acid test (NAT) result performed by the local Organ Procurement Organizations (OPOs) per standard UNOS policy. Additional donor inclusion criteria included a terminal serum creatinine less than $3 \mathrm{mg} / \mathrm{dL}$, a projected cold ischemia time less than 36 hours, and a pre-implantation renal biopsy that showed no evidence of chronic histologic changes in the donor kidney.

Donor hepatitis $\mathrm{C}$ antibody and qualitative $\mathrm{HCV}$ nucleic acid testing was performed in accordance with UNOS-mandated deceased donor testing using any FDA-approved assay by the OPO offering the kidney. These results were available at the time of organ offer. Donor serum HCV RNA quantification and genotype were performed in parallel with the transplant and results were available within 7 days of transplant. HCV RNA quantification was performed using the COBAS ${ }^{\circledR}$ AmpliPrep/COBAS ${ }^{\circledR}$ Taqman ${ }^{\circledR}$ HCV Test, v2.0 or cobas ${ }^{\circledR}$ 
HCV for cobas ${ }^{\circledR} 6800$ (lower limit of quantification for both 15 international units $/ \mathrm{ml}$ ). $\mathrm{HCV}$ genotype was performed with the LiPA ${ }^{\circledR}$ assay (Quest Diagnoistics) with reflex testing for NS5A resistance associated substitutions (RASs) at positions 28, 30, 31, and 93 if genotype 1a was identified.

GZR-EBR (100/50 mg) was administered orally to the HCV- transplant recipient on-call to the operating room for the kidney transplant. Post-exposure prophylaxis after D+/Rtransplantation varied according the donor HCV testing. For KT cases with donors infected with genotype 1a without NS5a RASs, genotype 1b, or genotype 4, GZR-EBR was continued daily for 12 weeks. For genotype 1a with NS5a RASs: ribavirin was added to GZR-EBV for 16 weeks. For genotype 2 or 3, SOF $400 \mathrm{mg}$ daily was added to GZR-EBR and continued for 12 weeks from the day of SOF initiation. When the donor genotype could not be determined due to insufficient viral load, GZR-EBR alone was continued for 12 weeks.

Induction immunosuppression consisting of intravenous methylprednisolone and intravenous rabbit anti-thymocyte globulin was followed by maintenance immunosuppression therapy consisting of tacrolimus, mycophenolate mofetil, and prednisone. Prophylaxis for other posttransplant infections included trimethoprim-sulfamethoxazole for Pneumocystis jirovecii pneumonia, valganciclovir for cytomegalovirus (CMV) infection in cases of CMV seropositive donors and/or recipients, and clotrimazole for oral candidiasis.

\section{Recipient Clinical Assessments}

Other on-treatment assessments were performed at 1-4 week intervals and included physical exam, review of medications and safety assessments, and evaluations of renal function, hemoglobin levels, and liver function. Glomerular filtration rate (GFR) was calculated using the Chronic Kidney Disease Epidemiology Collaboration (CKD-EPI) equation.(24) Posttreatment assessments included safety assessments through follow-up week 12 after treatment.

\section{Recipient Virologic Assessment and Treatment Response}

Recipient serum HCV RNA was measured using the Roche COBAS Ampliprep TaqMan HCV Test, v2.0 on day 0 prior to transplantation, on post-operative day one (POD1), and at treatment week (TW) 1, 2, 3, 4, 8, 12 through the end of treatment. The lower limit of quantification (LLOQ) was $15 \mathrm{IU} / \mathrm{ml}$. Post-treatment, serum HCV RNA was measured at follow-up week off treatment 2, 4, 8, 12. In cases of donor genotype 2 or 3 where SOF was added, TW corresponds to week of treatment with the three-drug combination.

\section{Recipient Immunologic Assessments}

Recipient HCV antibody testing was measured at baseline using Advia Centaur (Siemens) and at follow-up week 12 off treatment.

Evaluation of HCV-specific CD8+ T cell responses were assessed by IFN- $\gamma$ ELISpot using a matrix of 73 peptides corresponding to previously described optimal cytotoxic $\mathrm{T}$ lymphocyte epitopes predominantly for genotype 1, each peptide pool containing 7 to 12 peptides.(25) 
Briefly, peripheral blood mononuclear cells (PMBCs) were separated using a FicollHypaque. ELISpot plates were coated with $5 \mu \mathrm{g} / \mathrm{mL}$ anti-human IFN $\gamma\left(\mathrm{mAb} 4^{\circ} \mathrm{C}\right.$ overnight (MAbTech). Plates were washed and blocked with 10\% FBS in RPMI1640 media for $2 \mathrm{~h}$ at $37^{\circ} \mathrm{C}$ after which $2 \times 10^{5} \mathrm{PBMC}$ were plated with one of $22 \mathrm{HCV}$ peptide pools or control peptides against CMV, Epstein Barr virus, and Influenza at a final concentration of 10 $\mu \mathrm{g} / \mathrm{mL}$. Plates were incubated at $37^{\circ} \mathrm{C}$ for $15-20 \mathrm{~h}$ in a humidified incubator at $5 \% \mathrm{CO}_{2}$. The following day, plates were washed 7 times with PBS/0.05\% Tween 20 . Detection antibody (biotylated mouse anti-human IFN- $\gamma$ mAb, MAbTech) was added at a final concentration of $0.5 \mu \mathrm{g} / \mathrm{mL}$ for $2 \mathrm{~h}$ at RT. Plates were then washed 4 times as described above and alkaline phosphatase-conjugated anti-biotin $\mathrm{mAb}$ (Vector Laboratories) was added for $2 \mathrm{~h}$ at RT. Plates were developed with BCIP/NBT Solution (ThermoFisher Scientific) and spots counted using the AID iSpot Spectrum (Advanced Imaging Devices). Only pools in which $\mathrm{HCV}$ specific responses were $>50$ spot forming cells/million PBMC were considered positive.

\section{Statistical Analysis}

The primary safety endpoint was the incidence of adverse events related to DAA treatment in participants. The primary efficacy endpoint was the proporition of patients with an HCV RNA < LLOQ at follow-up week 12 after discontinuation of DAAs in all patients who were enrolled and received study drugs. We used Fisher's exact test to determine whether high donor RNA (>10,000 IU/mL) was associated with recipient HCV antibody responses at follow-up week 8 . We used a two-sided a of 0.05 to indicate a statistically signicant difference. All statistical analyses were performed using Stata 14 SE (College Station, TX).

\section{Study Oversight}

This study was approved by the Johns Hopkins Medicine Institutional Review Board and was conducted in compliance with Good Clinical Practice guidelines. The study was reviewed by the Food and Drug Adminstration and was determined to be exempt from requiring an IND. The investigators designed the study, conducted the protocol and wrote the manuscript. Study drug and funding were provided by Merck Pharmaceuticals.

\section{RESULTS}

\section{Recipient Characteristics}

Fifteen patients on the deceased donor transplant list at Johns Hopkins Hospital were approached for the study, and the first 10 to consent were enrolled in the study and received kidney transplants from HCV+ donors. Median age of recipients was 71 years (IQR 57-76) (Table 1). Eight recipients were male and 8 were white. The median time on the transplant waitlist prior to study enrollment was 4.2 months (IQR 0.9-18.3) and the median time to transplant after enrollment was 1 month (IQR .7-2) (Table 1).

\section{Donor Characteristics}

Median age of accepted HCV+ donors was 30 years (IQR 23-35) (Table 1). Five donors were female and all were white. All 10 donors were brain dead and cause of death was drug overdose $(n=6)$, trauma $(n=3)$ and cardiovascular $(n=1)$. The median Kidney Donor Profile 
Index (KDPI) score (on a scale from 0 to $100 \%$, with higher values indicating a greater predicted risk of graft failure for an individual kidney) was 45\% (IQR 32-48) (Table 1). All donor kidney biopsy findings were considered acceptable for transplantation, including the absence of significant chronic histologic changes. (Appendix Table 1, available at Annals.org) Two donors $(3,5)$ received significant transfusions and had samples for $\mathrm{HCV}$ testing that met criteria for hemodilution using an FDA approved hemodilution calculation. Three of the organs (donors 1, 6, 10) underwent pulsatile perfusion at the local OPO following recovery from the donor and prior to being transported to $\mathrm{JHH}$ for transplantation into the recipient. One donor kidney was from the local OPO, one kidney was from an OPO within the same UNOS region, and 8 kidneys were from OPOs outside of our region.

\section{Donor HCV Testing}

Hepatitis $\mathrm{C}$ antibody screening (Table 2) and qualitative HCV nucleic acid testing was positive in all 10 donors using approved UNOS assays. Donor 3 had an HCV RNA which was not detected with subsequent quantitative HCV RNA testing; samples from this donor met criteria for hemodilution due to significant transfusion requirements in the donor prior to testing. Median HCV viral load was 62,400 international units (IU)/mL (range < LLOQ 2,090,042 IU/mL) (Table 2). Donor genotypes were 1a $(\mathrm{n}=3), 1 \mathrm{a} / 3 \mathrm{mix}(\mathrm{n}=1), 2(\mathrm{n}=2)$, and in 4 cases HCV genotype could not be determined due to insufficient HCV RNA.

\section{Recipient HCV Treatment}

All 10 recipients received one dose of GZR-EBR on-call to the operating room. The median time between the first dose of GZR-EBR and reperfusion of the transplanted kidney was 5.1 hours (IQR 3.5-7.7 hours). Seven recipients completed treatment with only GZR-EBR daily for 12 weeks as they had donors who were infected with wild-type HCV genotype 1a or had an unknown genotype due to insufficient HCV RNA. No recipients required the addition of ribavirin as there were no NS5A RASs detected. Three recipients had SOF added to GZREBR after the donor HCV infection was identified as non-genotype 1. No delays in SOF initiation or dose modifications to SOF were required for any recipients. Specifically, SOF was initiated on POD12 in recipient 4 with a genotype $1 \mathrm{a} / 3$ mix donor, on POD6 in recipient 8 with a genotype 2 donor and on POD9 in recipient 7 with a genotype 3 donor. Treatment continued with SOF in combination with GZR-EBR for an additional 12 weeks after initiation of SOF. There were no adverse events related to DAAs in any recipient.

\section{Recipient On-Treatment and Follow-up HCV RNA}

In 7 out of 10 recipients, HCV RNA was <LLOQ (15 IU/mL) at all time points (Table 2 and Figure 1). Two recipients had low levels of HCV RNA detected within 24 hours of transplant (POD1) and undetectable HCV RNA at all other timepoints. For these two recipients, the donors were infected with wild-type genotype 1a with HCV RNA levels greater than 1 million IU/mL ( $4.65 \times 10^{6}$ and $1.1 \times 10^{6} \mathrm{Iu} / \mathrm{mL}$, respectively). One recipient received a donor with genotype $2 \mathrm{HCV}$ infection and initiated SOF on POD6. This recipient had an HCV RNA of $136 \mathrm{IU} / \mathrm{mL}$ on POD1 and $55 \mathrm{IU} / \mathrm{mL}$ at TW1 with undetectable HCV RNA at all other timepoints on treatment. In all 10 recipients, HCV RNA was not detected at any of the follow-up visits after completion of GZR-EBR \pm SOF treatment. No participant had virologic or clinical evidence chronic $\mathrm{HCV}$ infection. 


\section{Recipient Renal and Liver Function}

The median creatinine at follow-up week 12 off treatment was $1.05 \mathrm{mg} /$ deciliter (range 0.9-

2) and the median estimated GFR was $63.5 \mathrm{ml} / \mathrm{min}$ per $1.73 \mathrm{~m}^{2}$ (IQR $47.8-69.9 \mathrm{ml} / \mathrm{min}$ per $1.73 \mathrm{~m}^{2}$ ). The median cold ischemia time was 29 hours (IQR $22.6-32.6$ hours). Four recipients $(1,4,5,10)$ experienced delayed graft function defined as the need for renal replacement therapy in the first 7 days post-transplant. One of these recipients had an $\mathrm{HCV}+$ donor with genotype 2 infection and required SOF treatment. He had a GFR > $60 \mathrm{ml} / \mathrm{min}$ $\mathrm{ml} / \mathrm{min}$ per $1.73 \mathrm{~m}^{2}$ at the time of SOF initiation on POD12. No recipient developed highgrade proteinuria (defined as a urine protein creatinine ratio greater than 1 or a urine dipstick results greater than 1+) during $\mathrm{HCV}$ prophylaxis through 6 months post-transplant (Appendix Table 2, available at Annals.org). No recipient developed acute rejection or required a kidney biopsy for any reason during the follow-up period.

One participant (recipient 4) developed an elevation in transaminase levels greater than 5 times the upper limit of normal (Figure 2). There were no associated clinical symptoms. Peak AST was 188 (POD9) and peak ALT 214 (POD7); both decreased to the normal range by POD14 without any intervention. The donor HCV RNA level was 46,733 IU/ml, donor genotype was mixed 1/3a, and HCV RNA was detected in the recipient only on POD1 (below the limit of quantification). SOF was added to GZR/EBR on POD12. Bilirubin remained within normal limits. No other recipients had transaminase or bilirubin elevations during study follow-up.

No recipient required reoperation during the study period. Recipient 3 developed a distal ureteral stricture that required management with a percutaneous nephroureteral stent on POD30, followed by serial balloon ureteroplasty and eventual stent removal.

\section{Recipient HCV Antibody Responses}

All recipients had negative $\mathrm{HCV}$ antibody tests at baseline. Five recipients had reactive $\mathrm{HCV}$ antibody tests at follow-up week 12 off treatment and five did not (Table 2). For those who had reactive $\mathrm{HCV}$ antibody responses, the corresponding donor $\mathrm{HCV}$ genotypes were: not determined $(n=1), 1 a(n=2)$, genotype $2(n=1)$ and genotype $3(n=1)$. The median donor HCV RNA for these recipients was $1.01 \times 10^{6} \mathrm{IU} / \mathrm{mL}$ compared to a median donor $\mathrm{HCV}$ RNA of 928,524 IU/mL for recipients with nonreactive HCV Ab tests. Six HCV+/Rtransplants involved donors with HCV RNA $>10,000 \mathrm{IU} / \mathrm{mL}$. There were no significant associations between donor HCV RNA $>10,000 \mathrm{IU} / \mathrm{mL}$ or recipient HCV RNA detected at POD1 and recipient HCV antibody seroconversion at follow-up week 8 off treatment ( $p$ > $0.5)$.

\section{HCV T cell Responses}

The development of T-cells that recognize new HCV epitopes is a sensitive measurement of $\mathrm{HCV}$ replication even in the absence of viremia and can be used to detect infection, reinfection and superinfection. (26) Using a previously described method (25), we tested PBMCs from all recipients for responses to 73 optimal HCV peptides in pools of 7-12 peptides. A positive response to a peptide pool was defined as the presence of $>50 \mathrm{IFN}-\gamma$ SFU/million cells. Additionally, PMBC were tested for responses to a mitogen and a pool of 
CMV, EBV and influenza (CEF) peptides. Response to the mitogen and CEF peptides were observed in all participants demonstrating that post-transplant immunosuppression did not inhibit T-cell responses completely. Four recipients had no positive response to HCV pools at either baseline or week 8 (Figure 3). Three recipients recognized a peptide pool at TW8 that was not recognized pre-transplant, potentially indicating new responses. We were unable to resolve the new responses to the individual peptide/s within each positive pool due to limited numbers of PBMCs. Overall these data suggest HCV T cell responses may have developed in three transplant recipients and not in the other seven individuals with no change nor increase in $\mathrm{HCV}$ pools recognized.

\section{DISCUSSION}

This single-center open-label pilot study evaluated the use of kidneys from HCV+ donors for transplantation in $10 \mathrm{HCV}$ - recipients using direct-acting antivirals as pre- and posttransplant prophylaxis. The median wait time from study entry to KT was one month. There were no adverse events related to treatment. No recipients developed chronic HCV infection.

In 2012, Flohr et al reported on the use of kidneys from $13 \mathrm{HCV}$-antibody positive donors for transplantation in older $\mathrm{HCV}$ - recipients with no $\mathrm{HCV}$ treatment. Donor to recipient HCV transmission occurred in 7/13 (54\%) cases; these 7 recipients had a high rate of transaminitis (6/7) with one HCV-related liver death occurring at 5 months post-transplant. In this series, donor HCV NAT results were not available so some donors might not have had active $\mathrm{HCV}$ infection.(27)

More recently with the advent of IFN-free DAAs, Goldberg and colleagues performed HCV $\mathrm{D}+/ \mathrm{R}-$ transplantation in the THINKER trial, an open label single group pilot study of GZR-EBR as pre-emptive treatment for HCV in HCV- recipients receiving a kidney from an $\mathrm{HCV}+$ donor with genotype 1 infection. In THINKER, HCV- recipients were monitored for $\mathrm{HCV}$ viremia starting at POD 3. Once HCV RNA was detected, GZR-EBR was initiated for a 12 week treatment course. HCV donor-to-recipient transmission occurred in $100 \%$ of recipients with two cases of elevated transaminase levels. However, all recipients eventually achieved a sustained virologic response at week 12 after treatment.(28)

Our study is the first to explore a strategy of DAAs as pre- and post-exposure prophylaxis for HCV D+/R- transplantation. This prophylaxis was safe and effective in preventing the establishment of chronic HCV infection in all our recipients. Moreover, it may also have prevented acute $\mathrm{HCV}$ infection in some recipients. In our study, 5 recipients never had any detectable plasma HCV RNA; 4 had low level HCV RNA only on post-operative day 1, and one had low level HCV detected up to one week post-transplant. There were no symptoms or clinical consequences observed with this low level viremia (peak $136 \mathrm{IU} / \mathrm{mL}$ ). Preventing acute viral hepatitis early post-transplant is ideal, since many KT recipients receive lymphocyte-depleting induction immunosuppression.

Our study design allowed for the use of organs from $\mathrm{HCV}+$ donors infected with any genotype and did not require additional virologic or genotypic assays to be done at the time of organ offer and allocation. Three donors in our study were found to have non-genotype 1 
infection which is consistent with trends in the HCV epidemic among young person who inject opiates in the United States. $(29,30)$ In THINKER, $50 \%$ of potential kidney donors were excluded due to non-genotype $1 \mathrm{HCV}$ infection which was detected using a rapid genotype assay.(31) The potential for a high rate of organ discard and the limited availability of rapid genotype testing represent potential limitations to this approach.

All HCV+ donors in our study were relatively young and white; six died from drug-overdose reflecting the national opioid epidemic. Notably, only $3 / 10 \mathrm{HCV}+$ donors had genotype 1a infection. Four donors had very low HCV RNA levels with an indeterminate genotype. In the case of donor 3, the qualitative HCV RNA may have been a false positive result or alternatively, the quantitative HCV RNA result may have been a false negative result due to hemodilution since this donor received massive transfusions prior to testing. For the 3 donors who had low but quantifiable HCV RNA levels, theymay have been recently infected with HCV. Studies of the acute-phase HCV viral dynamics among injection drug users demonstrate intermittent low level viremia and periods of undetectable viremia in this early period. $(32,33)$

We performed several virologic and immunologic studies to further explore whether our preand post- treatment strategy truly prevented infection or whether it simply treated an established early infection. Only five recipients ever had HCV RNA detected post-transplant at very low levels (peak $136 \mathrm{IU} / \mathrm{mL}$ ) which arguably could represent viral transfer from the donor kidney rather than production of new HCV particles from the recipient liver. However, we detected new HCV antibody responses in 5/10 recipients. Development of an HCV antibody response did not correlate with donor HCV genotype, donor HCV viral RNA level, or the presence of recipient low level HCV viremia post-transplant, however the sample size was small. It is unclear if the presence of these antibodies indicates infection of the recipient liver or a response to virus/antigen carried over with the donor organ. Three recipients had an increase in the number of $\mathrm{T}$ cell responses to pools $\mathrm{HCV}$ peptides; however these same individuals all had positive $\mathrm{T}$ cell responses detected pre-transplant, indicating that these responses may have been cross-reactive rather than specific to HCV.. We were unable to resolve the pools into individual peptides due to a limited number of PBMCs. This made it difficult to determine whether responses to new T-cell epitopes developed which would have provided stronger evidence that $\mathrm{HCV}$ replication occurred in the recipients. Ultimately, it is difficult to conclude whether our strategy functioned as true prophylaxis in all recipients or if it functioned as very early treatment of $\mathrm{HCV}$ infection. Nonetheless, our prophylactic treatment approach for $\mathrm{HCV} \mathrm{D+/R-} \mathrm{transplant} \mathrm{represents} \mathrm{an} \mathrm{alternative} \mathrm{to} \mathrm{waiting} \mathrm{to} \mathrm{treat}$ recipients until viral replication has increased to levels necessary to detect viremia.

The limitations of this study include the fact that it was a single-center non-randomized trial with a small number of recipients. Recipients were older, predominantly male, and white; however based on other DAA trials, there is no reason to believe that this strategy should be less effective in other age groups, women or non-white individuals. For our HCV T cell responses studies, we could not resolve individual peptide/s recognized within each pool due to limited PBMCs. 
In conclusion, in this open-label, non-randomized study, DAA prophylaxis for HCVuninfected transplant recipients of $\mathrm{HCV}+$ donor kidneys was safe and well-tolerated. There were no adverse events related to treatment and no cases of chronic hepatitis $\mathrm{C}$. This strategy should be further studied within carefully monitored clinical trials. If confirmed in larger studies, this strategy should markedly expand organ options and reduce mortality for HCVKT candidates.

\section{Acknowledgments}

Supported in part by a research grant from Investigator-Initiated Studies Program of Merck Sharp \& Dohme Corp. The opinions expressed in this paper are those of the authors and do not necessarily represent those of Merck Sharp \& Dohme Corp.

Alexandra Valsalmakis, MD for her assistance in HCV RNA testing.

The Living Legacy Foundation of Maryland for their assistance in evaluating deceased donors. FUNDING SOURCES

Supported in part by a research grant from Investigator-Initiated Studies Program of Merck Sharp \& Dohme Corp. C.M.D. is supported by the National Cancer Institute grant K23CA177321-01A1. M.G.B is supported by the National Institute of Diabetes and Digestive and Kidney Diseases by grant R01AG042504 To D.L.S. D. L. S. is also supported by grant K24DK101828 from the National Institute of Diabetes and Digestive and Kidney Diseases. M.S. is supported by National Institute of Allergy and Infectious Disease by grant K24DA034621.

\section{References}

1. Saran R, Robinson B, Abbott KC, Agodoa LY, Albertus P, Ayanian J, et al. US Renal Data System 2016 Annual Data Report: Epidemiology of Kidney Disease in the United States. Am J Kidney Dis. 2017; 69(3 Suppl 1):A7-A8. [PubMed: 28236831]

2. Wolfe RA, Ashby VB, Milford EL, Ojo AO, Ettenger RE, Agodoa LY, et al. Comparison of mortality in all patients on dialysis, patients on dialysis awaiting transplantation, and recipients of a first cadaveric transplant. N Engl J Med. 1999; 341(23):1725-30. [PubMed: 10580071]

3. Merion RM, Ashby VB, Wolfe RA, Distant DA, Hulbert-Shearon TE, Metzger RA, et al. Deceaseddonor characteristics and the survival benefit of kidney transplantation. JAMA. 2005; 294(21): 2726-33. [PubMed: 16333008]

4. Massie AB, Luo X, Chow EK, Alejo JL, Desai NM, Segev DL. Survival benefit of primary deceased donor transplantation with high-KDPI kidneys. Am J Transplant. 2014; 14(10):2310-6. [PubMed: 25139729]

5. Gill JS, Rose C, Pereira BJ, Tonelli M. The importance of transitions between dialysis and transplantation in the care of end-stage renal disease patients. Kidney Int. 2007; 71(5):442-7. [PubMed: 17228366]

6. Danovitch GM, Cohen DJ, Weir MR, Stock PG, Bennett WM, Christensen LL, et al. Current status of kidney and pancreas transplantation in the United States, 1994-2003. Am J Transplant. 2005; 5(4 Pt 2):904-15. [PubMed: 15760417]

7. Reese PP, Abt PL, Blumberg EA, Goldberg DS. Transplanting Hepatitis C-Positive Kidneys. N Engl J Med. 2015; 373(4):303-5. [PubMed: 26200976]

8. Kucirka LM, Singer AL, Ros RL, Montgomery RA, Dagher NN, Segev DL. Underutilization of hepatitis C-positive kidneys for hepatitis C-positive recipients. Am J Transplant. 2010; 10(5):123846. [PubMed: 20353475]

9. Rudd RA, Seth P, David F, Scholl L. Increases in Drug and Opioid-Involved Overdose Deaths United States, 2010-2015. MMWR Morb Mortal Wkly Rep. 2016; 65(5051):1445-52. [PubMed: 28033313] 
10. Goldberg DS, Blumberg E, McCauley M, Abt P, Levine M. Improving Organ Utilization to Help Overcome the Tragedies of the Opioid Epidemic. Am J Transplant. 2016; 16(10):2836-41. [PubMed: 27438538]

11. Weiner SG, Malek SK, Price CN. The Opioid Crisis and Its Consequences. Transplantation. 2017; 101(4):678-81. [PubMed: 28323774]

12. Bowring MG, Kucirka LM, Massie AB, Luo X, Cameron A, Sulkowski M, et al. Changes in Utilization and Discard of Hepatitis C-Infected Donor Livers in the Recent Era. Am J Transplant. 2017; 17(2):519-27. [PubMed: 27456927]

13. Chen K, Lu P, Song R, Zhang J, Tao R, Wang Z, et al. Direct-acting antiviral agent efficacy and safety in renal transplant recipients with chronic hepatitis $\mathrm{C}$ virus infection: A PRISMA-compliant study. Medicine (Baltimore). 2017; 96(30):e7568. [PubMed: 28746204]

14. Colombo M, Aghemo A, Liu H, Zhang J, Dvory-Sobol H, Hyland R, et al. Treatment With Ledipasvir-Sofosbuvir for 12 or 24 Weeks in Kidney Transplant Recipients With Chronic Hepatitis C Virus Genotype 1 or 4 Infection: A Randomized Trial. Ann Intern Med. 2017; 166(2):109-17. [PubMed: 27842383]

15. Fernandez I, Munoz-Gomez R, Pascasio JM, Baliellas C, Polanco N, Esforzado N, et al. Efficacy and tolerability of interferon-free antiviral therapy in kidney transplant recipients with chronic hepatitis C. J Hepatol. 2017; 66(4):718-23. [PubMed: 28039098]

16. Lin MV, Sise ME, Pavlakis M, Amundsen BM, Chute D, Rutherford AE, et al. Efficacy and Safety of Direct Acting Antivirals in Kidney Transplant Recipients with Chronic Hepatitis C Virus Infection. PLoS One. 2016; 11(7):e0158431. [PubMed: 27415632]

17. Saxena V, Khungar V, Verna EC, Levitsky J, Brown RS Jr, Hassan MA, et al. Safety and efficacy of current direct-acting antiviral regimens in kidney and liver transplant recipients with hepatitis C: Results from the HCV-TARGET study. Hepatology. 2017; 66(4):1090-101. [PubMed: 28504842]

18. Roth D, Nelson DR, Bruchfeld A, Liapakis A, Silva M, Monsour H Jr, et al. Grazoprevir plus elbasvir in treatment-naive and treatment-experienced patients with hepatitis $\mathrm{C}$ virus genotype 1 infection and stage 4-5 chronic kidney disease (the C-SURFER study): a combination phase 3 study. Lancet. 2015; 386(10003):1537-45. [PubMed: 26456905]

19. Jacobson IM, Gordon SC, Kowdley KV, Yoshida EM, Rodriguez-Torres M, Sulkowski MS, et al. Sofosbuvir for hepatitis $\mathrm{C}$ genotype 2 or 3 in patients without treatment options. N Engl J Med. 2013; 368(20):1867-77. [PubMed: 23607593]

20. Lawitz E, Poordad F, Gutierrez JA, Wells JT, Landaverde CE, Evans B, et al. Short-duration treatment with elbasvir/grazoprevir and sofosbuvir for hepatitis C: A randomized trial. Hepatology. 2017; 65(2):439-50. [PubMed: 27770561]

21. Foster GRKA, Cramp ME, Moreea S, Barclay S, Collier J, Brown AS, Ryder SD, Ustianowski A, Forton DM, Fox R, Gordon F, Rosenberg WM, Mutimer DJ, Du J, Gilbert CL, Robertson M, Barr E, Haber B. Elbasvir/grazoprevir plus sofosbuvir in treatment-naive and treatment-experienced cirrhotic patients with hepatitis $\mathrm{C}$ virus genotype 3 infection treated for 8,12 , or 16 weeks: final results of the C-ISLE study. Journal of Hepatology. 2017; 66(1):S503-S4.

22. Levitsky J, Formica RN, Bloom RD, Charlton M, Curry M, Friedewald J, et al. The American Society of Transplantation Consensus Conference on the Use of Hepatitis C Viremic Donors in Solid Organ Transplantation. Am J Transplant. 2017

23. Kling CE, Perkins JD, Landis CS, Limaye AP, Sibulesky L. Utilization of Organs From Donors According to Hepatitis C Antibody and Nucleic Acid Testing Status: Time for Change. Am J Transplant. 2017

24. Levey AS, Stevens LA, Schmid CH, Zhang YL, Castro AF 3rd, Feldman HI, et al. A new equation to estimate glomerular filtration rate. Ann Intern Med. 2009; 150(9):604-12. [PubMed: 19414839]

25. Cox AL, Mosbruger T, Lauer GM, Pardoll D, Thomas DL, Ray SC. Comprehensive analyses of CD8+ T cell responses during longitudinal study of acute human hepatitis C. Hepatology. 2005; 42(1):104-12. [PubMed: 15962289]

26. Osburn WO, Fisher BE, Dowd KA, Urban G, Liu L, Ray SC, et al. Spontaneous control of primary hepatitis $\mathrm{C}$ virus infection and immunity against persistent reinfection. Gastroenterology. 2010; 138(1):315-24. [PubMed: 19782080] 
27. Flohr TR, Bonatti H, Hranjec T, Keith DS, Lobo PI, Kumer SC, et al. Elderly recipients of hepatitis C positive renal allografts can quickly develop liver disease. J Surg Res. 2012; 176(2):629-38. [PubMed: 22316669]

28. Goldberg DS, Abt PL, Blumberg EA, Van Deerlin VM, Levine M, Reddy KR, et al. Trial of Transplantation of HCV-Infected Kidneys into Uninfected Recipients. N Engl J Med. 2017; 376(24):2394-5. [PubMed: 28459186]

29. Uccellini L, Tseng FC, Monaco A, Shebl FM, Pfeiffer R, Dotrang M, et al. HCV RNA levels in a multiethnic cohort of injection drug users: human genetic, viral and demographic associations. Hepatology. 2012; 56(1):86-94. [PubMed: 22331649]

30. Hope VD, Hickman M, Ngui SL, Jones S, Telfer M, Bizzarri M, et al. Measuring the incidence, prevalence and genetic relatedness of hepatitis $\mathrm{C}$ infections among a community recruited sample of injecting drug users, using dried blood spots. J Viral Hepat. 2011; 18(4):262-70. [PubMed: 20456636]

31. Goldberg DVV, Farooqi M, Sicilia A, Hasz R, Bloom R, Blumberg E, Gentile C, Abt P, Reese P. Hepatitis C Genotypes Among Deceased Organ Donors in the United States. Am J Transplant. 2017; 17(Supplement 3)

32. Cox AL, Netski DM, Mosbruger T, Sherman SG, Strathdee S, Ompad D, et al. Prospective evaluation of community-acquired acute-phase hepatitis C virus infection. Clin Infect Dis. 2005; 40(7):951-8. [PubMed: 15824985]

33. Glynn SA, Wright DJ, Kleinman SH, Hirschkorn D, Tu Y, Heldebrant C, et al. Dynamics of viremia in early hepatitis C virus infection. Transfusion. 2005; 45(6):994-1002. [PubMed: 15934999] 


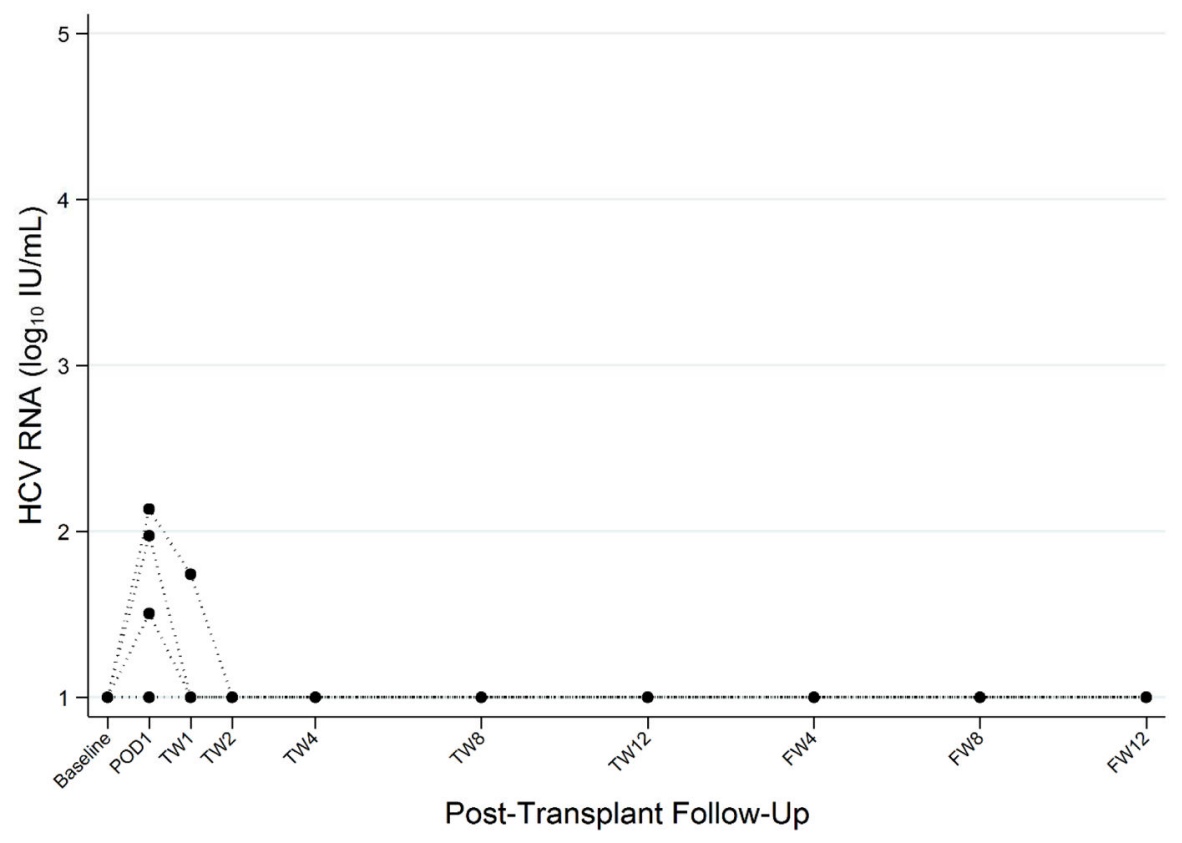

Figure 1. Pre- and Post-transplant HCV RNA Among HCV-uninfected Recipients of HCV+ Donor KT

HCV plasma RNA $\log _{10} \mathrm{IU} / \mathrm{mL}$ pre-transplant, during DAA treatment on post-operative day 1, post transplant weeks 1, 2, 4, 8 and 12 and after DAA treatment on follow-up weeks 4, 8, and 12 . Lower limit of quantification is $15 \mathrm{IU} / \mathrm{mL}$. 
(A) ALT

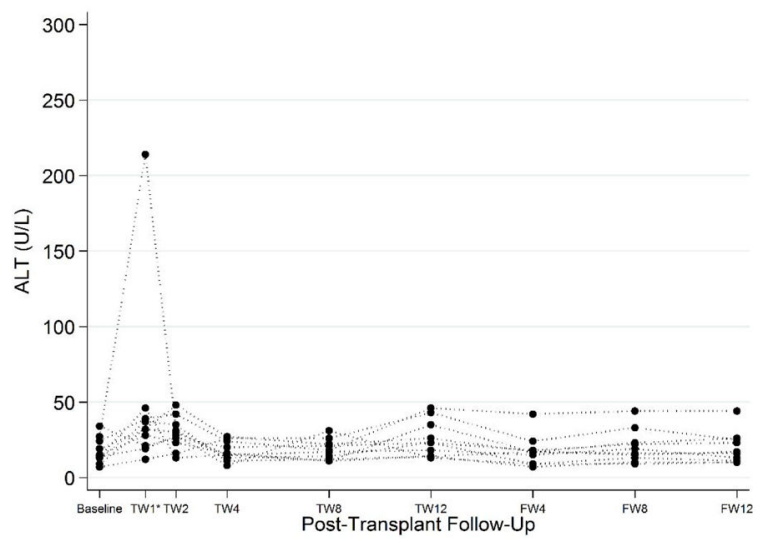

(B) AST

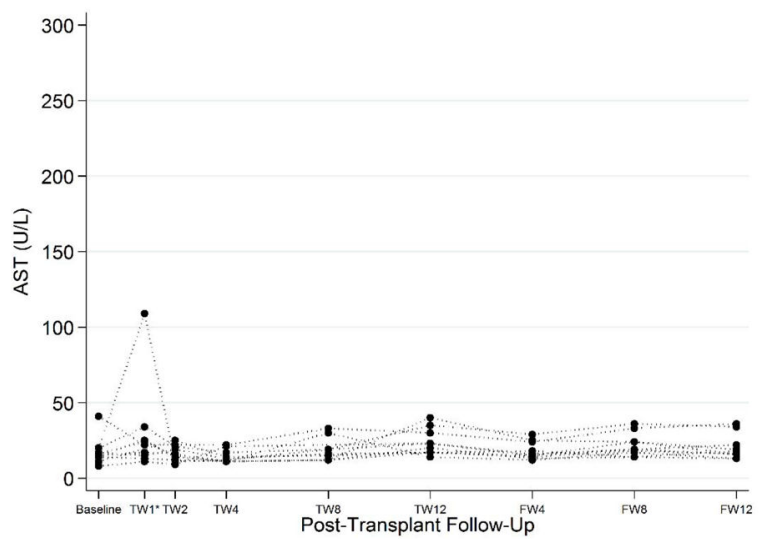

*Missing for one patient

Figure 2. Post-transplant Liver Function Tests Among HCV-uninfected Recipients of HCV+ Donor KT

(A) ALT values and (B) AST values measured at baseline and during post-transplant follow up.

*Missing for one patient 


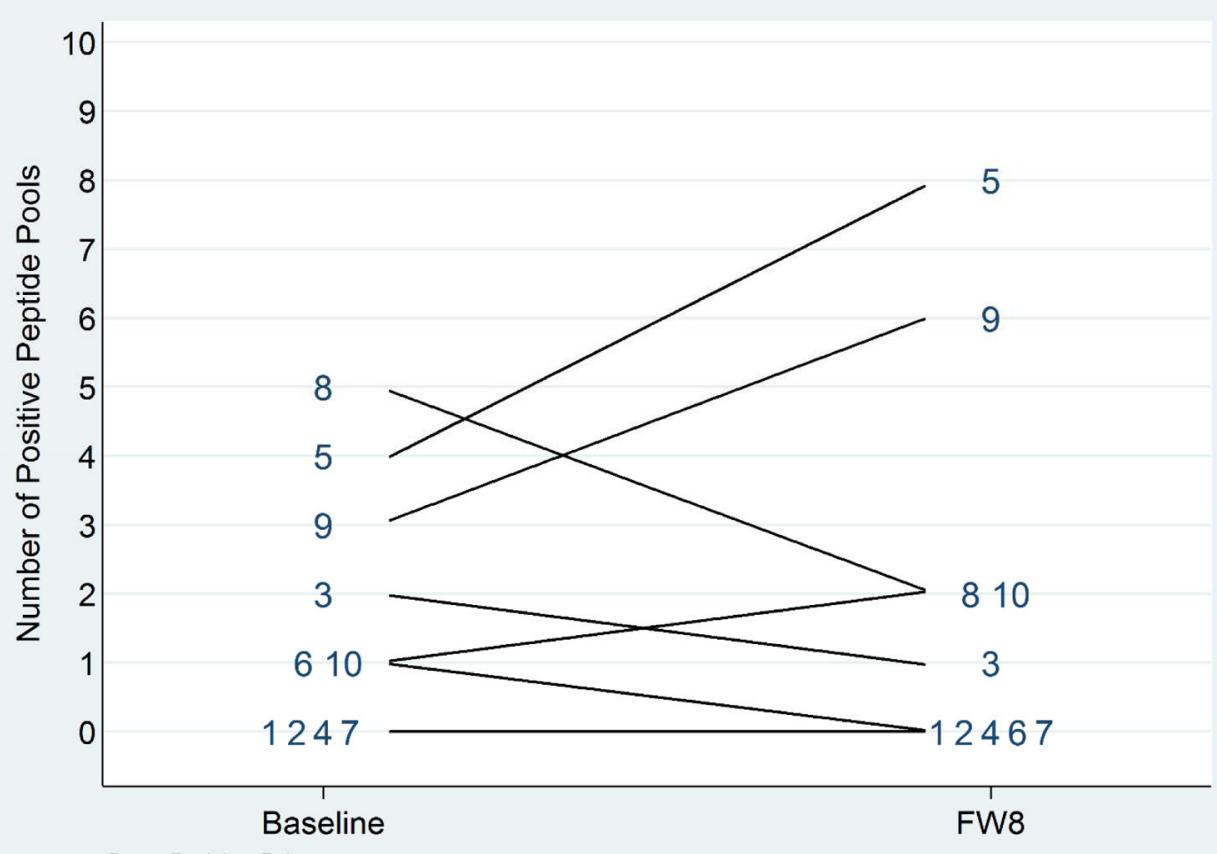

Figure 3. Pre- and Post-Transplant HCV-specific CD8+ T cell Responses among Among HCVuninfected Recipients of HCV+ Donor KT

The number of positive peptide pools identified for each recipient pre-transplant and at follow-up week 8 post-transplant are shown. T cell responses were measured by IFN- $\gamma$ ELISpot using a matrix of 6 peptide pools containing overlapping peptides of optimal cytotoxic T lymphocyte HCV epitopes. Pools with > 50 spot forming cells/million PBMC were considered positive. 


\section{Table 1}

\section{Recipient and Donor Characteristics}

\begin{tabular}{lc}
\hline HCV- Recipient characteristics & $\mathbf{N = 1 0}$ \\
\hline Age at transplant (Med (IQR)) & $71(65-72)$ \\
Female & $2(20 \%)$ \\
Race & \\
$\quad$ White & $8(80 \%)$ \\
Black & $1(10 \%)$ \\
Asian & $1(10 \%)$ \\
Primary cause of renal failure & \\
Polycystic Kidney Disease & $2(20 \%)$ \\
Diabetes/Hypertension & $3(30 \%)$ \\
Glomerulonephritis & $1(10 \%)$ \\
IgA Nephrosclerosis & $1(10 \%)$ \\
NSAID Use/Interstitial nephritis/Lithium toxicity & $3(30 \%)$ \\
Blood Type & \\
O & $6(60 \%)$ \\
A & $1(10 \%)$ \\
B & $2(20 \%)$ \\
AB & $1(10 \%)$ \\
Years on dialysis pre-transplant (Med (IQR)) & $1.6(0.0-2.6)$ \\
Months on waitlist prior to study (Med (IQR)) & $4.2(0.9-18.3)$ \\
Months on waitlist in study (Med (IQR)) & $1.0(0.7-2.0)$ \\
\hline HCV+ Donor characteristics & \\
\hline Age (Med (IQR)) & $3(90 \%)$ \\
Female & $3(60 \%)$ \\
Race & \\
Wrause of death & \\
\hline
\end{tabular}




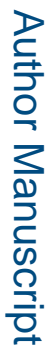

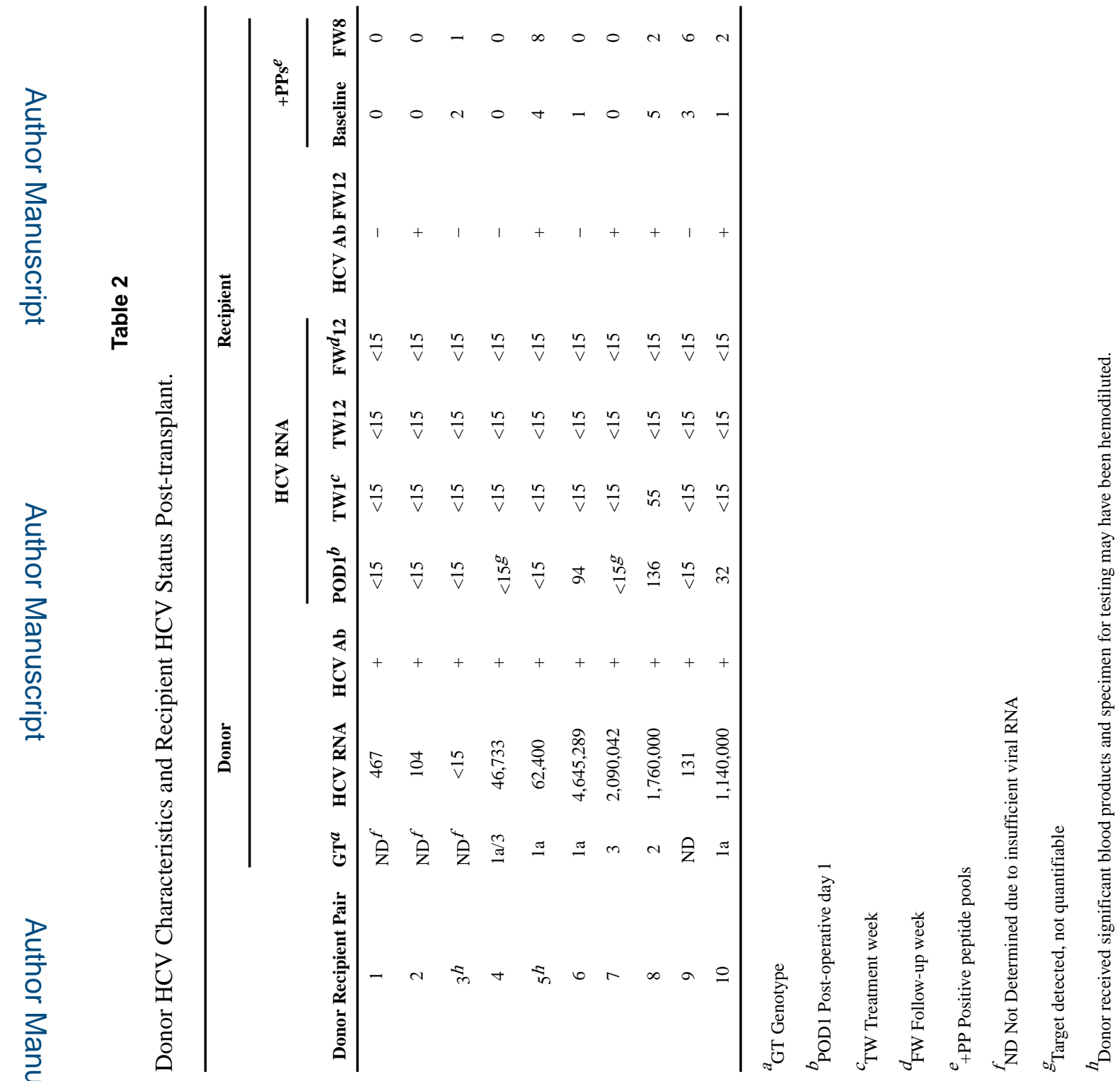

Ann Intern Med. Author manuscript; available in PMC 2018 October 17. 